\title{
SIMULTANEOUS ENDOSCOPIC RADIAL ARTERY AND GREAT SAPHENOUS VEIN HARVESTING FOR REDO CORONARY ARTERY BYPASS GRAFTING. A REPORT OF TWO CASES.
}

\author{
Martin Simek*, Petr Nemec, Pavel Marcian, Marek Gwozdziewicz, Ivo Fluger
}

\author{
Department of Cardiac Surgery, Teaching Hospital and Faculty of Medicine and Dentistry, Palacky University, Olomouc, \\ Czech Republic \\ *e-mail:martin.simek@c-mail.cz
}

Received: August 15, 2007; Accepted: September 24, 2007

Key words: Radial artery/Saphenous vein/Endoscopic harvesting/Coronary artery bypass grafting

Aim: An ageing population and increase in patient co-morbidities are forcing cardiac surgeons to meticulously consider the benefits and risks of respective conduits and their harvesting techniques.

Case reports: Two cases of simultaneous endoscopic radial artery and great saphenous vein harvesting, for redo coronary artery bypass grafting, are presented. A shortage of venous conduits after previous bypass grafting, as well as the presentation of several risk factors of wound-healing complications, favoured simultaneous utilisation of both endoscopic techniques.

Conclusion: Endoscopic vessel harvesting together with the pre-harvesting duplex study is able to gain not only high-quality conduits but also minimize the risk of wound-healing and neurological disturbances associated the saphenous vein and radial artery harvesting.

\section{INTRODUCTION}

Endoscopic vessel harvesting for coronary artery bypass grafting $(\mathrm{CABG})$ is a safe and reliable method ${ }^{1,2}$. Endoscopic radial artery (ERAH) and great saphenous vein harvesting $(\mathrm{EVH})$ techniques are associated with a significant reduction in wound-healing and neurological complications as well as less pain and better cosmetic results in comparison with traditional harvesting ${ }^{1-3}$. Redo coronary artery bypass grafting (redo-CABG) for either progression of coronary artery disease or conduit occlusion requires harvesting of additional conduits. An ageing population and increase in patient co-morbidities are forcing cardiac surgeons to consider the benefits and risks of respective conduits and their harvesting techniques, particularly if risk factors of wound-healing disturbances such as obesity, diabetes, peripheral vascular disease, chronic obstructive pulmonary disease and immunosuppression are presented ${ }^{3}$.

Simultaneous endoscopic harvesting of the great saphenous vein and radial artery unifies the advantages of both endoscopic procedures and can be carried out either by two surgeons utilizing two endoscopic devices at the same time, or by one surgeon performing harvesting successively with one endoscopic instrument. In both cases presented bellow, the endoscopic vessel harvesting was carried out by one surgeon, the EVH followed the ERAH. The system using $\mathrm{CO}_{2}$ insufflation was used (Vasoview 6 ${ }^{\mathrm{TM}}$, Boston Scientific/Guidant, Diegelen, Belgium) and a pneumatic tourniquet was applied to secure forearm ischemia during ERAH ( ref. $^{4}$ ).
Case 1

A 67-year-old male underwent venous coronary artery bypass grafting on LAD, OM and RCA 16 years ago. Coronary angiography indicated for a rapid worsening of exertional angina within the previous 4 months, revealed occlusion of all three venous bypasses as well as the progression of native coronary artery disease. Severe obesity (BMI 40), insulin-dependent diabetes and chronic obstructive pulmonary disease represented significant risk of sternal and leg wound-healing complications in the post-operative course. Moreover, only a limited segment of the great saphenous vein in the right upper thigh area was available because of previous harvesting. The Duplex ultrasound study showed an up to $20 \mathrm{~cm}$ long suitable saphenous vein segment (diameter $4 \mathrm{~mm}$ ). Furthermore, there were no pathological changes in either of the radial arteries (diameter 2.5-2.8 $\mathrm{mm}$, intima-media thickness $<0.3 \mathrm{~mm}$ ). Collateral palmar flow was sufficient based on the Allen test and triplex ultrasound study. The patient underwent redo-CABG and the skeletonized left internal mammary artery was grafted to LAD, the radial artery to PDA, and a venous conduit sequentially to OM and the diagonal branch. The harvesting time of the ERAH and the EVH reached 48 and $34 \mathrm{~min}$, respectively. The postoperative course was complicated by acute exacerbation of the chronic pulmonary disease. There was no evidence of either wound-healing or neurological disturbances following endoscopic vessel harvesting.

\section{Case 2}

A 61-year-old male had undergone triple coronary artery bypass grafting 13 years ago. Coronary angiography, carried out for refractory angina, revealed a patent left internal mammary artery grafted to LAD, while both 


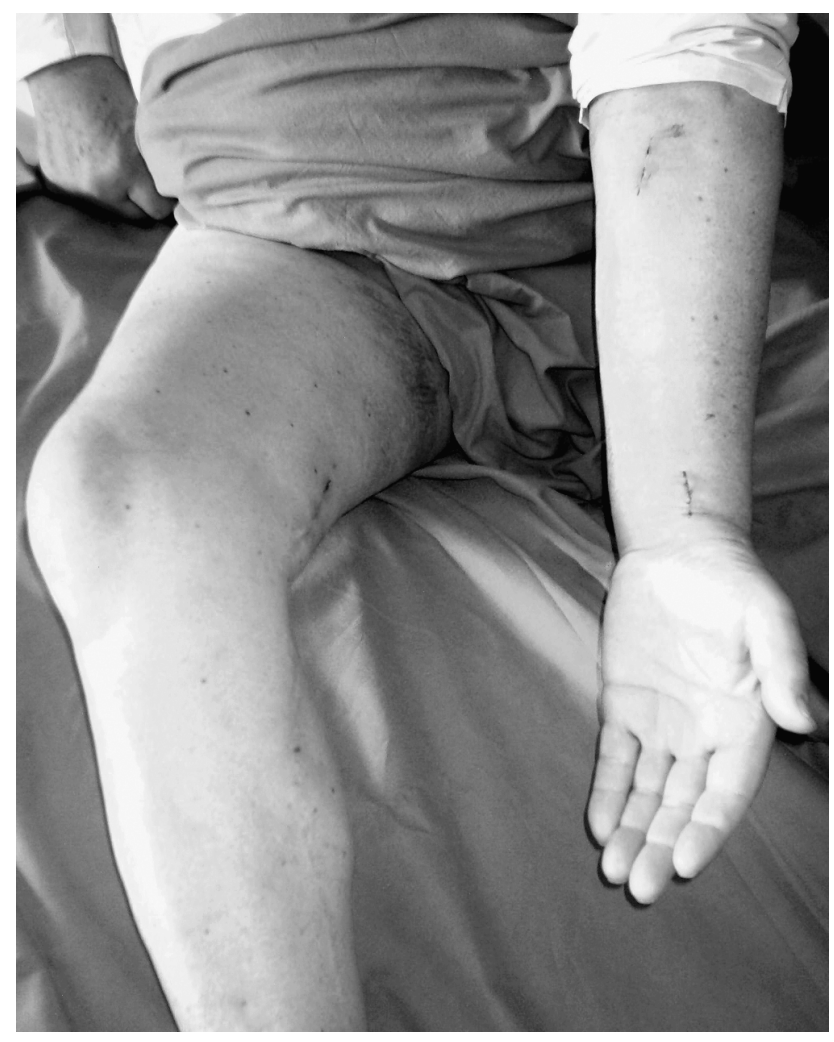

Fig. 1. The result of simultaneous endoscopic vein and radial artery harvesting.

venous bypasses grafted to OM branch and RCA were occluded. Because PCI was not feasible, the patient was indicated for redo-CABG. Likewise, obesity (BMI 34) and non-insulin dependent diabetes were presented as well as limited length of the great saphenous vein. The Duplex study described appropriate size of the venous segment (diameter $<5 \mathrm{~mm}$ ) in the right thigh area, at the level above the scar of previous harvesting. Both radial arteries showed physiological triphasic flow with no wall changes (diameter 2.4-2.6 mm, intima-media thickness $<0.4 \mathrm{~mm}$ ). The palmar arch was fully competent based on the Allen test and the triplex ultrasound study as well. A great saphenous vein segment was grafted to RCA and consequently the radial artery to OM branch. The endoscopic vessel harvesting took $47 \mathrm{~min}$ for the ERAH and 38 min for the EVH. The post-operative course was uneventful, only a small local haematoma in the right thigh area after EVH was presented (Figure 1).

\section{DISCUSSION}

Endoscopic vessel harvesting is primarily accepted for the great saphenous vein, once the learning curve is mastered, comparable harvesting characteristics (i.e., harvesting time, length of conduits, and the number of injuries) with traditional vein harvesting techniques are achieved ${ }^{1}$. Significant reduction in leg-wound complications in the post-operative period as well as in the long-term follow-up were clearly documented, particularly in the presentation of wound-healing risk factors involving obesity, diabetes, peripheral vascular disease and immunosuppression ${ }^{1-3}$. ERAH, for the present time not so widely accepted, is associated predominantly with reduction in neurological disturbances whose high incidence following traditional radial artery harvesting has been repeatedly reported ${ }^{5,6}$. Although doubts about the durability of endoscopically harvested conduits exist, several analyses have shown no differences in endothelial injury, angiographic outcomes and 5-year event-free survival in comparison with traditionally harvested conduits ${ }^{1,7}$. In redo cases, the majority of candidates are elder, have advanced atherosclerotic coronary artery disease and significant co-morbidities compared with primary procedures. Thus, the risk and benefit of harvesting additional conduits should be carefully considered. Moreover, the clinical examination has its limitation in the conduit quality assessment. Further investigation should be carried out prior to harvesting in relation to gain high-quality conduits ${ }^{8,9}$. The great saphenous vein as well as the radial artery are easily accessible for ultrasound study. Inappropriate internal vein diameter after distension $(>5 \mathrm{~mm})$, wall changes as well as the presence of varicose segments should be easy to identify and excluded from harvesting. Accordingly, the hypoplastic radial artery (diameter $<1.2 \mathrm{~mm}$ ), its pathologic wall changes (intima-media thickness $>5 \mathrm{~mm}$, calcifications) and stenotic flow pattern exclude the use of this conduit ${ }^{4}$. Evaluation of the equal-sided ulnar artery, its flow parameters and wall changes together with the palmar arch competency should follow, despite negativity of the Allen test ${ }^{9}$.

\section{CONCLUSION}

The shortage of conduits together with the presence of risk factors affecting wound-healing processes is frequent in patients undergoing redo-CABG. Well-mastered endoscopic vessel harvesting and the pre-harvesting duplex study determining conduit appropriateness are able to gain high-quality conduits with very low risk of woundhealing and neurological disturbances if the saphenous vein and the radial artery as conduits are considered.

\section{ABBREVIATIONS:}

BMI - body mass index

LAD - left anterior descending artery

OM - obtuse marginal artery

RCA - right coronary artery

PDA - posterior descending artery

\section{REFERENCES}

1. Cheng D, Allen K, Cohn W, et al. Endoscopic vascular harvest in coronary artery bypass grafting surgery: a meta-analysis of randomized trial and controlled trials. Innovations 2005; 1:61-74.

2. Aziz O, Athanasiou T, Darzi A. Minimally invasive conduit harvest- 
ing: a systematic review. Eur J Cardiothorac Surg 2006; 29:324333.

3. Allen KB, Heimansohn DA, Robinson RJ. Risk factors for leg wound complications following endoscopic versus traditional saphenous vein harvesting. Heart Surg Forum 2000; 4:325-330.

4. Simek M, Marcian P, Bruk V et al. Endoscopic radial artery harvesting for coronary artery bypass grafting: fist experience Rozhl Chir 2006; 85:416-421.

5. Denton TA, Trentoa L, Cohen M. Radial artery harvesting for coronary bypass operations: neurological complication and their potential mechanisms. J. Thorac Cardiovasc Surg 2001; 121:951956.
6. Patel AN, Henry C, Hunnicutt C, et al. Endoscopic radial artery harvesting is better than the open technique. Ann Thorac Surg 2004; 78:149-153.

7. Allen KB, Heimansohn DA, Robison RJ. Influence of endoscopic versus traditional safenectomy on event-free survival: five-year follow-up a prospective randomized trial. Heart Surg Forum 2003; 6:143-145.

8. Cohn DJ, Korver KF. Optimizing saphenous vein site selection using intraoperative venous duplex ultrasound scanning. Ann Thorac Surg 2005; 79:2013-2017.

9. Agrifoglio M, Dainese L, Pasotti S, et al. Preoperative assessment of the radial artery for coronary artery bypass grafting: is the clinical Allen test adequate? Ann Thorac Surg 2005; 79:570-572. 